Article

\title{
The Lebanese Electricity Woes: An Estimation of the Economical Costs of Power Interruptions
}

\author{
Elie Bouri ${ }^{1, *}$ and Joseph El Assad ${ }^{2}$ \\ 1 USEK Business School, Holy Spirit University of Kaslik 1, Jounieh, Lebanon \\ 2 Faculty of Sciences, Holy Spirit University of Kaslik 2, Jounieh, Lebanon; josephalassad@usek.edu.lb \\ * Correspondence: eliebouri@usek.edu.lb; Tel.: +961-9-600-861
}

Academic Editor: Robert Lundmark

Received: 12 June 2016; Accepted: 12 July 2016; Published: 27 July 2016

\begin{abstract}
This paper contributes to the political and scientific debate surrounding the economic costs entailed by the regular power cuts in Lebanon. Examining the data on electricity consumption that was produced by onshore and offshore power plants, this paper estimates the economical costs of power interruptions in Lebanon over the period 2009-2014. Based on 700 USD/MWh, representing the average value of lost load (VOLL) in that period, results indicate that electricity shortages continue to render significant transfers of wealth to the detriment of economy and society as a whole. Over the period 2009-2014, the total losses for the Lebanese economy reached 23.23 billion USD. Just as importantly, some evidence suggests a sharp decline in the economical costs of power interruptions with the inception of the two floating power plants in 2013. The results are crucial for the decision makers to identify the economic efficiency of alternative measures to enhance the security of the Lebanese electricity supply.
\end{abstract}

Keywords: electricity outage costs; security of electricity supply; floating power plants; Lebanon

\section{Introduction}

Access to a reliable and continuous supply of electricity, as a major element of infrastructure services, is essential to all economic activities (Gurgul and Lach [1]). It also contributes to the enhancement of the standard of living of citizens and the technological and scientific advancement of societies.

In Lebanon, however, ensuring such access has remained a major challenge. Since the end of the civil war in the early 1990s, Lebanon has never enjoyed an acceptable degree of electricity supply security. Recent figures show that electricity consumption per capita has grown at an average rate of $7 \%$ per year, whereas electricity generation has always lagged behind (Fardoun, Ibrahim, Younes, and Louahila-Gualous [2]). A closer look at the electricity supply/demand balance indicates that the electricity demand in Lebanon is outstripping the supply, leading to electricity supply shortages, which in turn cause regular power cuts across all parts of the country. More than $7.5 \%$ of electricity demand (1116 GWh) has been imported from Syria and Egypt through the regional interconnection grid. As the Syrian war intensified in 2011, Lebanon became more like an energy island; electricity imports were disrupted and a substantial (new) demand for electricity was provoked by the influx of thousands of Syrian refugees to Lebanon, leading to a wider electricity capacity shortage. In an attempt to replace those crucial imports, the Lebanese authorities rented two Turkish power ships in 2013.

Alongside this gloomy snapshot appears an eminent need for action to restore a sufficient level of electricity supply security by way of considering new generation capacity (both floating and non-floating). To this end, an estimation of the economic cost of power interruptions arises as an eminent and crucial step towards informing future electricity planning (Coll-Mayor, Pardob, 
and Perez-Donsion [3]). In particular, this estimation can be used to make decisions about maintenance and investments that reduce the probability of supply cuts. Prior studies, however, have provided very limited information on the economic cost of power interruptions in Lebanon. In this regard, the calculation of the value of lost load (VOLL) has proved a major challenge and a prerequisite step in the estimation of the cost of power interruptions. In addition, Electricite du Liban (EDL), the sole official provider of electricity in Lebanon, and private generators have long co-existed, making the Lebanese case an interesting field of research. Since the early 1990s, private back-up generators started spreading across the country offering their electricity output for neighborhoods during chronic power interruptions. Clearly, the rising cost of electricity bills on private generators is putting a strain on household budgets. More recently, the use of floating power plants to generate electricity has added to the particularity of the local electricity sector.

A detailed review of the recent literature shows that numerous studies attempted to deal with the electricity problem in Lebanon. Some of these studies proposed reform plans and useful insights for the sustainability of the electric sector, while others contained recommendations and policy suggestions for the usage of renewable energy sources. Chedid and Ghajar [4] examined the merits of implementing energy efficiency policies in the building sector in Lebanon and provided recommendations to remove the major barriers hindering the penetration of energy efficiency options in the Lebanese market. El-Fadel, Hammond, Harajli, Jones, Kabakian, and Winnett [5] focused on the evaluation of the local electricity sector in terms of its sustainability. Dagher and Ruble [6] constructed scenarios for Lebanon's electricity sector. The authors examined the shift toward natural gas in one scenario and toward renewable energy sources in another scenario. Fardoun, Ibrahim, Younes, and Louahila-Gualous [2] summarized the technical problems at the level of electricity generation, transmission and distribution, as well as the administrative and financial states, and presented some interesting suggestions. Hamdan, Ghajar, and Chedid [7] focused on the electrical energy policy for Lebanon, which was proposed by the Ministry of Energy and Water (MEW) in 2010 (Bassil [8]). The authors assessed the impact of policy implementation on energy production, overall cost, technical/commercial losses and reliability. Kinad and Elkhoury [9] presented an overview of the current renewable energy status in Lebanon. The authors focused on barriers hindering improvements and proposed relevant solutions. Najjar, Ghoulam, and Fares [10] assessed the feasibility and reliability of implementing hybrid-renewable distributed energy systems. Ibrahim, Fardoun, Younes, Louahila-Gualous, and Ghandour [11] presented a review of the energy status, conventional and renewable, and illustrated their problems with the suggested recommendations.

However, none of the aforementioned studies have explicitly attempted to estimate the cost of power interruptions, and considered for the role of floating power plants. Recently, the employment of power ship plants to fulfill electricity shortages in some developing countries has gained a lot of attention from policy makers because a power ship is appreciated for its low cost-to-power ratio and for its high flexibility. To fill this literature gap, this paper focuses on the implications of electricity interruptions for Lebanese consumers and the local economy by estimating the economic cost of power interruptions. In particular, the need for this study arose from the fact that in the past few years, the Lebanese authorities have been struggling to deliver a reliable and continuous supply of electric energy to the end users. No estimations of this kind have been published in recent years. More interestingly, the analyses quantify the economical consequences of power interruptions monetarily by comprising the volume of electricity generated by the two Turkish power ships. Considering the literature review in Section 3, and coping with existing data limitations in Lebanon, this paper adopted a mathematical model along the general lines of Coll-Mayor, Pardob, and Perez-Donsion [3] to estimate the economic cost of power interruptions. The flexibility and easy to apply features make this model, which is based on the production function-based approach, the most suitable one to estimate the economic cost of power interruptions in Lebanon.

The key contributions in this paper are four-fold. First, this paper estimates, for the first time, the economical losses of power interruptions in Lebanon within an empirical model. While Lebanese 
regulators and policy-makers are well aware that electricity shortage is a major concern for the overall economic activity, quantifying those losses monetarily will help policy-makers to allocate capital more optimally in the energy space to one of the country's most binding constraints on economic output. Second, unlike prior studies that attempted to offer remedies to the electric power system in Lebanon by focusing on the implementation of energy efficiency options or the usage of renewable energy sources, this paper takes into account the volume of electricity generated by the two Turkish power ships, and emphasizes the short-run effects of floating power generation on the reduction of electricity shortage and thereby on the cost of outage. This would provide regulators and policy makers with more exhaustive analyses, which would lead to the inference of more appropriate regulatory choices. Third, this paper provides additional economic insights about the role of power ships by comparing three types of existing power generation (thermal, hydraulic, and international imports). Finally, this paper uncovers the hidden costs incurred by users of private generators on the local economy.

The rest of the paper proceeds as follows. Section 2 provides an overview of the electric sector in Lebanon, including electricity generation, consumption, and pricing. Section 3 reviews the related literature and describes the research model. Section 4 presents and discusses the empirical results. Finally, Section 5 concludes the paper.

\section{The Lebanese Electricity System}

\subsection{Electricity Generation}

The official power generation in Lebanon is of three types: thermal, hydraulic, and international imports from both Syria and Egypt. In 2009, the imports from Syria and Egypt were 589 MWh and $527 \mathrm{MWh}$ respectively, constituting more than $7.5 \%$. Unfortunately, due to regional problems, these imports have not been stable and have encountered several fluctuations during the last four years.

However, the generation capability itself is characterized by inefficiencies in the power plants due to their deteriorating conditions (Fardoun, Ibrahim, Younes, and Louahila-Gualous [2]). The high degree of electrification combined with the estimated electricity demand growth suggests that Lebanon needs to both optimize the current electricity system and increase the installed capacity. However, policy makers and industry specialists have deemed the solution to increase the installed capacity unrealistic, given the weak underlying economic conditions in Lebanon (El-Fadel, Hammond, Harajli, Jones, Kabakian, and Winnett [5]).

In 2010, the Lebanese government adopted the electricity reform plan designed by the MEW (Bassil [8]). This plan outlined a complete restructuring of the whole electrical sector divided into three steps: short, medium, and long term. The initial milestones of the plan were set in 2012, 2014, and beyond 2015. Essentially, the paper focused on presenting the main features of the generation plan for all three terms. The ultimate target on the generation side was to reach a total installed capacity of 4,000 MW by 2014 and 5,000 MW beyond 2015. This would allow EDL to meet the rising demand and have a margin of a spinning reserve. For this purpose, the plan outlined renting $271 \mathrm{MW}$ from floating barges to serve as a stop-gap solution in the short term. This should have been accompanied by a rapid increase of the installed capacity by $600-700 \mathrm{MW}$, using several technologies that would be financed by the Lebanese government. The possibility of importing electricity, through power purchase agreements (PPAs) from Turkey was also considered but unfortunately was not possible because of the security situation in the region. This should also have been synchronized with the rehabilitation of existing power plants, leading to an increase in the capacity up to $245 \mathrm{MW}$. In the medium and long term, the plans outlined an increase of the installed capacity by 2,500 MW using independent power producer (IPP) modality with the collaboration with the private sector, along with the introduction of renewable energies through biomass, wind farms, and the rehabilitation of existing and the commissioning of new hydro plants. The investment needed by the Lebanese government for the restructuring of the generation sector was estimated to be between 988 and 1,114 million USD; the investment needed by the private sector was estimated to be between 2,645 and 2,745 million USD; 
and, finally, 880 million USD were estimated to be needed by international loans. This does not cover the cost of importing from Turkey nor the cost of electricity bought from the floating barges.

Nowadays, imports from Turkey are not possible, as previously mentioned. In addition, the rehabilitation plan has been postponed, and two barges were connected to the electrical grid in 2013 and 2014. All these delays in the implementation of the plan, which have mainly been due to political reasons, have intensified the burden of EDL.

\subsection{Electricity Consumption}

Due to the failure of EDL in providing a continuous electricity service, self-generation has emerged. World Bank [12] estimates that self-generation with a total estimated capacity of $900 \mathrm{MW}$ satisfies $33 \%-38 \%$ of electricity consumption in Lebanon. The Lebanese government has long turned a blind eye to operators of private generators, even though they are causing a high bill for the importation of petroleum (El-Fadel, Hammond, Harajli, Jones, Kabakian, and Winnett [5]) and are selling electricity to the public at a largely higher cost compared to EDL tariffs (Hamdan, Ghajar, and Chedid [7]).

\subsection{Electricity Pricing in Lebanon}

With more than 1.5 million official customers, EDL has been adopting a freezing tariff policy since 1994. The current average tariff for domestic use is 9.58 US cents per $\mathrm{kWh}$, whereas small industries pay a flat rate of $7.63 \mathrm{US}$ cents per $\mathrm{kWh}$. In 2009, the average cost of electricity stood at 17.14 US cents per $\mathrm{kWh}$, of which $62 \%$ (10.77 US cents per $\mathrm{kWh}$ ) goes to fuel costs, while generation, transmission, and distribution constitute the remaining costs.

Beside the official EDL bill, households and shops pay another bill to private generators at a largely higher cost of 45 US cents per kWh (Hamdan, Ghajar, and Chedid [7]). The large difference between private generator fees and EDL tariffs represents an additional constraint to personal consumption and thus to economic growth.

Furthermore, EDL has been depending on the Lebanese government's budget to cover its mounting losses. Subsidies to domestic electricity production in the form of direct payments to EDL have been increasing in Lebanon over the last three decades. They increased from 62 million USD in 1998 to 2.026 billion USD in 2013, implying an annual compounded growth rate of $26.17 \%$. EDL losses impose one of the largest burdens on the public budget. In 2013, electricity subsidies reached 2.20 billion USD or $14.85 \%$ of the government budget. This sum is equivalent to more than $21.5 \%$ of national revenue or $4.6 \%$ of national GDP. It also contributed an astonishing $3.2 \%$ of the national debt burden.

\subsection{Power Ships in Lebanon}

As previously indicated, rental power plants emerged as an optimal solution to replace Syrian and Egyptian imports. In June 2013, Lebanon installed its first 187.5 MW power ship (KPS9) near the Zouk plant to supply emergency power to the region of Mount Lebanon. Later, in September 2013, a second power ship (KPS7) with an estimated power capacity of 83.5 MW was installed in Jieh. Using heavy fuel oil, both ships provide around $20 \%$ of Lebanon's electricity needs or approximately two additional hours of electricity supply. The decision to opt for another power ship made perfect sense because of its flexibility and short loading time. Additionally, its flexibility to the EDL in terms of fuel and its ability to be relocated to wherever the power is needed imply that power ships represented an obligatory choice in the short term. The project had an average cost of $4.8 \mathrm{US}$ cents $/ \mathrm{kWh}$, excluding the fuel cost. In addition, the latest available figures indicate that the total cost of electricity production of the two power ships averaged 19.33 US cents/kWh.

In this study, the electricity produced by the two power ships was used in order to present the total official generation, demand, and deficit for the period 2009-2014. Figure 1 outlines the evolution of the generation, demand, and deficit of electrical energy between 2009 and 2012. As shown, the deficit 
of electrical energy declined to 7,295 GWh in 2013 and to 5,524 GWh in 2014 following the connection of the two floating plants to the national grid.

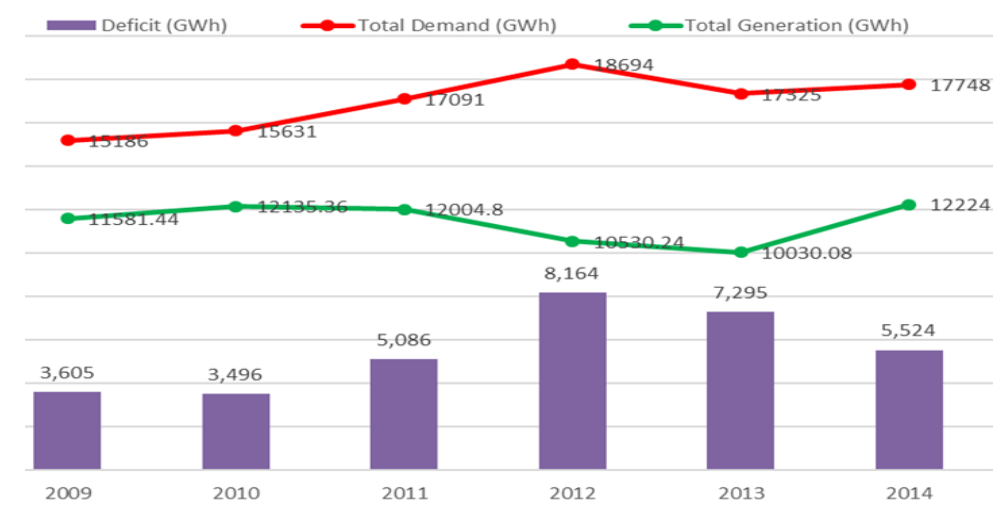

Figure 1. Demand, generation and deficit of electrical energy including the power ships. Source: EDL.

\section{Methodology}

This section overviews the literature on the cost of power interruptions and summarizes the related methodological approaches to estimate them. The final paragraph specifies the most appropriate model for the case of Lebanon.

\subsection{Related Literature Review}

The topic of estimating the costs of power interruptions has constantly attracted the attention of policy-makers and researchers. Earlier studies have considered the case of developed countries. Given the availability of detailed data in these countries, most of the studies have estimated the power outage cost at the country level as well as the sector and region levels. In a case study approach focusing on the power interruptions that occurred in the US on 14-15 August 2003, Lacommare and Eto [13] estimated the cost to electricity consumers, indicating that the annual cost for power interruptions to US electricity consumers was around 79 billion USD. In Germany, Praktiknjo, Hahnel, and Erdmann [14] proposed a survey-based model to analyze the costs of power interruptions; Praktiknjo [15] used online survey data within a two-staged bottom-up regression model and implied that power interruptions are in average relatively expensive for residential consumers. The author also showed that the duration of a power interruption has a significant impact on the magnitude of the interruption costs. In Sweden, Carlsson and Martinsson [16] used choice experiment survey data within a random parameter logit model, whereas Carlsson, Martinsson, and Akay [17] used open-ended contingent valuation survey on a case study and focused on the willingness-to-pay for reducing power outages. In the Netherlands, De Nooji, Bijvoet, and Koopmans [18] estimated interruptions costs in terms of lost production and lost leisure time. In Austria, Reichel, Schmidthaler, and Schneider [19] used both a survey and production function approach and assessed economic losses caused by electricity outages as well as willingness-to-pay to avoid these power interruptions. They found that the effects of a simulated $12 \mathrm{~h}$ outage in all of Austria are disturbing to nearly all household and non-household consumers. In addition, households account for $22.9 \%$ of the electricity shortfall and for $5.9 \%$ of the total losses, which amount to 478 million EURO. In Spain, Linares and Rey [20] used the production function approach and estimated the economic impact of an electricity interruption in different sectors and regions. In Finland, Kufeoglu and Lethonen [21] employed a hybrid methodology based on a customer survey and production function and indicated that that the economic consequences of two interruptions with half an hour of duration each will be more severe than one interruption lasting one hour. In Cyprus, Zachariadis and Poullikkas [22] used the case study approach for estimating the unprecedented power shortages in summer 2011. The authors estimated the cost of electricity supply interruptions on the industrial, service and household sectors, and stressed on the importance of the 
response of energy authorities, which avoided substantial losses to the local economy. Later studies looked into in the case of developing countries where there is less efficient electric infrastructure base, and where power interruptions were more frequent. A study conducted in Sri Lanka by Wijayatunga and Jayalath [23] showed that power shortages can cause significant losses in the local industrial sector. The study used the production function approach and estimated the economic loss from $300 \mathrm{~h}$ of power interruption to be approximately in the range of $47-117$ million USD, which is $0.4 \%-0.9 \%$ of the country's GDP. In Cameroon, Diboma and Tatieste [24] used a survey and focused on the estimation of power interruption costs to industries. Their results showed that power interruption losses are very significant and seriously affected the local industrial operations. In South Korea, Kim, Nam, and Cho [25] applied survey data and considered the inconvenience cost of a rolling black out in the residential sector.

Following this section's review of the related literature, the next section overviews the methodological approaches that have been used to estimate the cost of power outage and then presents the most suitable approach for the case of Lebanon.

\subsection{Methodology}

As shown above, power interruptions, which provoke lost economic opportunities for the end consumer and for the overall economy, have been widely studied by researchers and practitioners. However, no consensus has been reached on how to estimate the values of those economical losses. A closer look into the above-mentioned literature points towards the existence of different analytical approaches for the estimation of power interruptions costs. Among all, three approaches have been extensively preferred by the electric power society: (1) consumer surveys; (2) case studies; and (3) production functions (Linares and Rey [20]).

The first methodological approach, which is based on stated preferences, relies on surveys of end consumers, who are particularly asked to assess the costs or losses that are incurred due to an electricity interruption (see Kufeoglu and Lethonen [21] and Beenstock, Goldin, and Haitovsky [26]). This approach draws consumers' preferences based on the willingness to pay for reliable services or willingness to accept interruptions. Even though this approach is the most commonly used in research, it is academically the most challenging one for the case of Lebanon, where such data are not available. In particular, it requires a data collection that is time-consuming and expensive. In addition, the consumer survey approach may suffer from considerable bias because consumers most often tend to overestimate their interruption costs to free-ride on the system (Linares and Rey [20]). Other issues associated with surveys include the possibility of poor measurement, omission of relevant cases, and non-response. Furthermore, the use of estimates from other countries is often inadequate. The second—case study—approach uses cost estimates from historical blackouts (see Lacommare and Eto [13], Carlsson, Martinsson, and Akay [17], Zachariadis and Poullikkas [22] and Corwin and Miles [27]). The most widely studied power outages include the New York outage of 1977 (Corwin and Miles [27]) the US Northeast blackout of 2003 (Lacommare and Eto [13]), and the power cuts in Sweden after storm Gudrun of 2005 (Carlsson, Martinsson, and Akay [17]). While the case study approach avoids the bias of the consumer survey method, its major shortcoming has been the difficulty to generalize the results because history will not always repeat itself (Linares and Rey [20]). Another shortcoming of this approach is that it is highly expensive to conduct. The third approach uses the production functions in order to estimate the consequences of outages through lost production or through lost time (see De Nooji, Bijvoet, and Koopmans [18] and Linares and Rey [20]). To this end, several choices can be made, such as the estimation of lost production in each sector or on the overall economic output. This production function approach typically infers power interruptions costs from linkages between macroeconomic figures. As such, it uses the ratio of an economic measure, such as gross domestic product or gross value added, and a measure of electricity consumption to estimate outage costs (Linares and Rey [20]). Although this approach is relatively flexible and easy to implement in the presence of disaggregated data, however, it has some disadvantages: under this 
approach, electricity is assumed to be an essential input for production, which is not always true; the fact that, in some sectors, production may be postponed or displaced to other time slots may lead to an overestimation of outage costs.

More complex production function approaches incorporating the role of resilience measures have been implemented by Rose, Oladosu, and Shu-Yi [28]. Other studies have also developed mixed approaches combining macroeconomic data with consumer surveys (Reichel, Schmidthaler, and Schneider [19]).

While the three most common methodologies to infer power interruptions costs were presented in the previous paragraphs, the Lebanese situation is such a complicated one that there was a need to conceive an augmented methodology in order to estimate the costs of power outage. In fact, surveys were not possible since most of the consumer database is not accessible to the public. In addition, electricity interruption is so common in Lebanon that rolling blackouts can persist up to $14 \mathrm{~h}$ per day and throughout the year. Lastly, electricity demand has to be considered from both the EDL side and the private generator side. In particular, the third approach is well suited and favored for Lebanon in terms of being easy and much cheaper than the other two approaches. More importantly, the third approach is capable of yielding highly objective estimations (Kufeoglu and Lethonen [21]), even though its application in Lebanon requires some adjustments.

While numerous production function-based approaches were employed in previous studies, Coll-Mayor, Pardob, and Perez-Donsion [3] proposed a simplified methodology, based on the VOLL, to estimate the economic losses of power outages in the Spanish industrial sector.

The next paragraph presents the mathematical model along the lines of Coll-Mayor, Pardob, and Perez-Donsion [3] used to estimate the economic losses of power outages in Lebanon, and implies whether there is an economic rationale for using power ships.

\subsection{Mathematical Model}

The approach offered by Coll-Mayor, Pardob, and Perez-Donsion [3], which is based on the production function, represents an appropriate approach to estimate outage costs for the case of Lebanon. The authors argued that their methodology is relatively easy to applicate and requires data input sources that are free of confidentiality issues, which fits our situation so exactly. However, Coll-Mayor, Pardob, and Perez-Donsion [3] argued that their methodology could be less efficient if it is used for company-specific cases. Positively, this was not the case for this study. In addition, the authors showed that the results obtained by their methodology did not differ considerably from the results obtained by other methodologies. This further motivates our choice of using their methodology. Furthermore, their model makes optimal use of currently available data. Given our objective of estimating the cost of power interruptions, their methodological framework appears to be a focal point for our study. In cases where data limitations at regional level prevent a direct application, the adopted model will be provided with additional assumptions and auxiliary approximations.

According to the mathematical model of Coll-Mayor, Pardob, and Perez-Donsion [3], formulated in Equation (1), the values of the economical losses represent the losses to individuals and businesses of being deprived of electrical energy.

$$
\mathrm{VECOL}=\mathrm{NPE} \times \mathrm{VOLL} \times \mathrm{ELP}
$$

where VECOL denotes the value of economical losses in USD, NPE means non-produced energy in hours, VOLL represents value of lost load in USD per kWh, ELP denotes equivalent lost power in GW.

The following paragraph contains the evaluation of the different parameters that were included in the above equation, in particular the VOLL. The latter was assessed in collaboration with the MEW and the World Bank. The reader can refer to Bassil [8] for a detailed description of the valuation of the VOLL. According to Equation (1), the assessment of economical losses is based on the evaluation of 
NPE as a benefit, which is not produced. In this regard, NPE data is an input that has to be known. However, the value of the NPE, which depends on many variables that include, among others, time of day, day in the week, and the level of automatizing of the industry is difficult to estimate. Clearly, this value is proportional to the length of power cut. As for the VOLL, it represents the lost consumer's surplus or producer's surplus associated with a lack of reliable electric supplies. While the VOLL can be estimated at different levels (regional, activity, and company), the lack of disaggregated data on activity and regional levels in Lebanon has forced us to use (aggregate) country level data (Bassil [8]). It is worth mentioning that the World Bank [12] has decomposed the VOLL into two key components: The first comprises the direct costs incurred by users of private generators to cope with the EDL's regular power interruptions, whereas the second includes the indirect losses to the Lebanese economy. The latest available figures for the period 2009-2013 show that the first component represents $54.71 \%$ of the VOLL, whereas the remaining $45.29 \%$ corresponds to the indirect economical losses. Finally, the ELP is the loss of power experienced in a power outage. As was the case with the NPE, the ELP depends on many variables that include the time of day or the day in the week in which the official power cut took place.

VECOL can also be formulated as the VOLL multiplied by the energy amount, which is not supplied. Accordingly, Equation (1) can be rewritten as:

$$
\mathrm{VECOL}=\mathrm{VOLL} \times(\mathrm{Ed}-\mathrm{Eg})
$$

where Ed and Eg are the electricity demand and electricity generation (respectively) expressed in kWh.

Even though mathematically the two Equations (1) and (2) are equivalent to each other, it seems that using Equation (2) to estimate the economical cost of power interruptions is more adequate to the Lebanese situation. This is simply because data available from the EDL are in the form of energy and not in the form of power. Accordingly, using available data on electricity demand and electricity generation as in Equation (2) considers the whole year as one time slot and thereby makes the analysis of the results on this basis.

\section{Results}

The following assumptions were necessary in order to carry out the analysis. Firstly, EDL will maintain the existing electricity tariff. Secondly, the costs of fuels will remain unchanged. Thirdly, all economic sectors and regions are equally affected by power outages. Fourthly, yearly data are used to analyze the economic impact of the loss of electricity.

The study was conducted using data covering the period from 2009 to 2014 (Ministry of Energy and Water [29]). As determined by the data availability, the analysis was kept as simple as possible and did not include the time-varying VOLLs. The paper also used data on electricity consumption produced offshore by EDL via the two power-ships. Using the year 2009 as a reference and based on Equation (1), VECOLs were estimated over the six-year period.

In addition, the analysis required the estimation of the VOLL, which represents an average cost per MWh for the study period. While the electricity reform plan, which was launched by the MEW in 2010, estimated that the range of the VOLL/MWh is 200 to 2,000 USD, the latest figures from EDL indicated that the VOLL/MWh was around 700 USD in the period 2009-2014. Using the six-year average cost of 700 USD and considering the deficits of electrical energy extracted from Figure 1, VECOLs from 2009 to 2014 were calculated (see Figure 2). For 2009, the VECOL was equal to 2.52 billion USD. As the deficit widened in 2011 and 2012 to reach 5,086 MWh and 8,164 MWh respectively, the economic costs of electricity shortfalls also increased. After peaking at around 5.72 billion USD in 2012 , the economic costs of electricity supply interruptions dropped steadily over the next two years to reach a low of 3.87 billion USD during 2014. 




Figure 2. Total cost of annual outages in billion USD. Source: Own calculations.

More analytically, the average cost of 700 USD can be decomposed into two key components: (1) the direct costs incurred by users of private generators to cope with the EDL's regular power cuts and (2) the indirect losses to the Lebanese economy. According to monthly indicative prices issued by the MEW in the period 2009-2013, the first component represents $54.71 \%$ of the average cost per MWh or 383 USD/MWh. Accordingly, the price of a MWh supplied by private generators was estimated to be around 383 USD, which represents $54.71 \%$ of the average price of 700 USD used in our study. Accordingly, the second component is estimated to be worth 317 USD/MWh, which represents the indirect impact of electric power interruptions on the overall Lebanese economy. Those two components are presented graphically in Figure 2.

Several crucial implications immediately emerge from Figure 2. First, the rate of decline in the total costs of electricity supply interruptions since the peak of 5.72 billion USD recorded in 2012 was significant, especially in 2014, when it reached $24.27 \%$. Otherwise stated, the total cost of outages decreased by 0.61 billion USD in 2013 and by 1.24 billion USD in 2014. One of the major causes for this substantial decline was the introduction of new generation sources to the Lebanese electrical grid. As previously indicated, two power ships (KPS7 and KPS9) with an installed capacity of $83.5 \mathrm{MW}$ and 187.5 MW respectively were connected in 2013 to the Zouk and Jieh power plants. The data from EDL also show that both floating power plants generated around 2,133 GWh in 2014. This additional generation capacity saved the Lebanese economy 1.493 billion USD. However, the cost of buying the electricity from the two Turkish power ships was around $19.33 \mathrm{US}$ cents $/ \mathrm{kWh}$, leading to an annual cost of 0.412 billion USD. Analytically, the difference between the theoretical savings of 1.493 billion USD and the effective savings of 1.24 billion USD represents more or less the total cost of electricity supplied by the two floating plants, KPS7 and KPS9.

Nevertheless, one could argue that the power ships represent an efficient solution to curb electricity shortages only because the average cost per kWh for the floating plants (19.33 US cents) is significantly lower than the VOLL, which was estimated at around 70 US cents (per kWh). Against this rationale, Figure 3 presents the latest electricity costs of the three types of power generation (thermal, hydraulic, and international imports from Syria and Egypt). By way of comparison, in 2012, floating power plants had one of the lowest electricity production costs: much lower than the average cost of energy generated by thermal plants $(21.56 \mathrm{USD} / \mathrm{kWh})$ and the average cost of imported energy (22.27 USD $/ \mathrm{kWh}$ ). The results indicate that the policy makers who designed the energy plan well considered the short-/medium-term value added by floating power plants. These plants have represented in the Lebanese context an economic advantage and an imperative window to fulfill partially the unsupplied electricity at competitive costs.

There are no earlier estimates for Lebanon to compare these results. However, focusing on Equation (1), the results of this study allow us to estimate the reduction in the levels of both NPE and ELP. In fact, the reduction in the energy gap between the generation and demand was reduced from 8,164 GWh in 2012 to 5,524 GWh in 2014. This reduction, which was mainly due to the introduction of the two power ships, can be seen in the reduction of the NPE level from 3,826 h in 2012 (based on 
a demand of 2,134 MW) to 2,727 $\mathrm{h}$ in 2014 (based on a demand of 2,026 MW). Otherwise stated, the introduction of power ships has reduced blackout periods of around 1,100 h per year or $3 \mathrm{~h}$ per day. This significant amelioration of power supply and its potential effects on all economic activities cannot be ignored by economic actors. The standard of living of Lebanese citizens of Lebanese citizens also will benefit from a relatively better power supply which contributes to the technological and scientific advancement of the local societies.

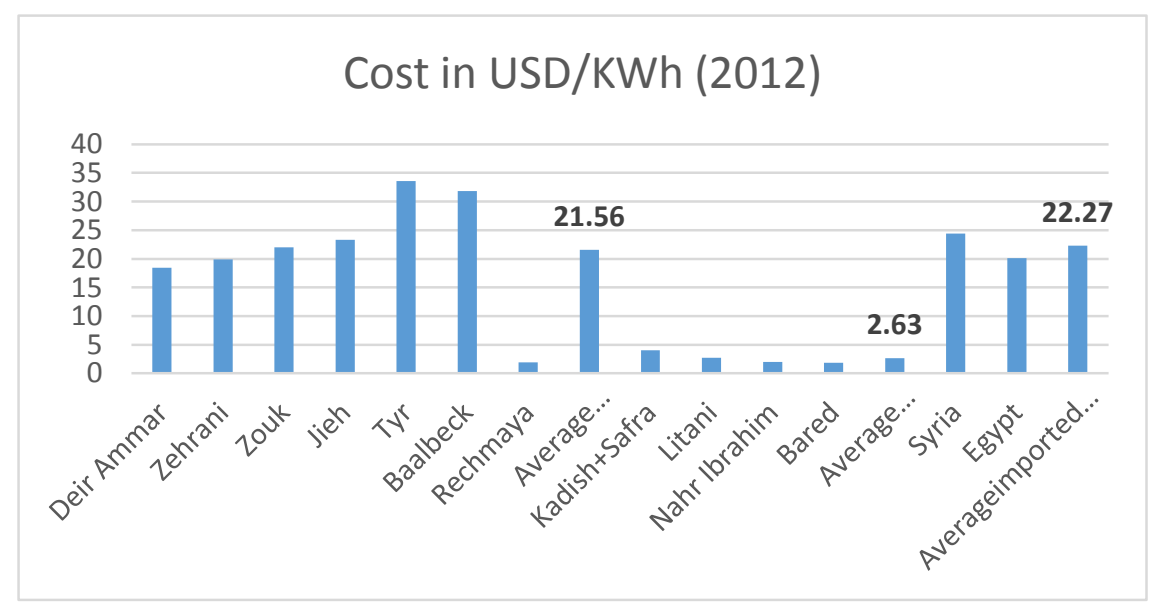

Figure 3. Costs of generating electricity from different plants. Note: Numbers in bold represent the average production cost in USD/kWh of each of the three official power generation sources in Lebanon: Thermal, hydraulic and international imports from both Syria and Egypt. Source: EDL.

\section{Conclusions}

Lebanon has always suffered from a significant supply/demand imbalance in the regulated electricity market. With almost $100 \%$ electrification, an electricity shortage in Lebanon could hold back both economic and social development. Using a simplified model in line with Coll-Mayor, Pardob, and Perez-Donsion [3], this paper quantified the costs of power cuts monetarily, even though the estimation of outage costs is often associated with many uncertainties (Zachariadis and Poullikkas [22]); the adopted model can be used to analyze the losses at regional as well as country levels (Coll-Mayor, Pardob, and Perez-Donsion [3]). Our study is a unique work by distinguishing itself from prior studies by depicting, within a simplified model, both the direct and indirect economic costs of power interruptions in the Lebanese context where the official electric generation coexists with the private one. In particular, this study contributes to the related literature by highlighting the role of floating power plants in reducing those costs and by positioning the two power ships, in terms of costs, within the existing power generation in Lebanon. The results indicated that interruption costs had substantial impacts on the local economy. Based on an average VOLL of 700 USD/MWh, results indicate that the total losses for the Lebanese economy reached 23.23 billion USD in the period 2009-2014. However, these costs have been declining since the inception of floating power plants in 2013. This paper therefore argued that the concept of using ready-to-operate power ships to generate electricity is distinctly appealing from an economic perspective for the short and medium term, as outlined by the MEW plan of 2010.

The information presented in this paper could prove useful to decision makers and industry specialists seeking to understand the stability and reliability of the electric sector. Intuitively, the use of power ships emerged as an optimal and time-effective solution to minimize these total costs, given their flexibility and low investment costs compared to thermal or imported electricity. Given that electricity shortages have socio-economic impacts on the nation at large, the Lebanese electrical system and thereby the Lebanese economy would benefit from a reduction in outage costs. Less spending by Lebanese households and businesses on the private generators, whose costs are substantially higher 
than those of EDL, suggests that consumers and businesses can invest in, spend in, and grow the local economy and improve the standard of living.

Finally, it is worth mentioning that one advantage of our approach was that it relied on the fact that the power cuts studied were representative of cuts in general, which makes it easy to generalize the empirical results. Nevertheless, this study was not free of limitations. It estimated and explored an aggregated level of the VECOL without accounting for the effects of power interruptions on disaggregated regional and sector levels (Praktiknjo [30]). The lack of reliable data about the power interruption costs across economic sectors and regions made us incapable of considering the differences across sectors and regions. Future research should attempt to address this assumption.

Acknowledgments: We would like to thank the Higher Center for Research at the Holy Spirit University of Kaslik (USEK) for covering the costs to publish in open access.

Author Contributions: E.B. and J.E. conceived and designed the experiments; J.E. performed the experiments and analyzed the data; E.B. wrote the paper.

Conflicts of Interest: The authors declare no conflict of interest.

\section{References}

1. Gurgul, H.; Lach, Ł. The electricity consumption versus economic growth of the Polish economy. Energy Econ. 2012, 34, 500-510. [CrossRef]

2. Fardoun, F.; Ibrahim, O.; Younes, R.; Louahlia-Gualous, H. Electricity of Lebanon: Problems and recommendations. Energy Procedia 2012, 19, 310-320. [CrossRef]

3. Coll-Mayor, D.; Pardob, J.; Perez-Donsion, M. Methodology based on the value of lost load for evaluating economical losses due to disturbances in the power quality. Energy Policy 2012, 50, 407-418. [CrossRef]

4. Chedid, R.; Ghajar, R. Assessment of energy efficiency options in the building sector of Lebanon. Energy Policy 2004, 32, 647-655. [CrossRef]

5. El-Fadel, R.; Hammond, G.; Harajli, H.; Jones, C.; Kabakian, V.; Winnett, A. The Lebanese electricity system in the context of sustainable development. Energy Policy 2010, 38, 751-761. [CrossRef]

6. Dagher, L.; Ruble, I. Modeling Lebanon's electricity sector: Alternative scenarios and their implications. Energy 2011, 36, 4315-4326. [CrossRef]

7. Hamdan, H.; Ghajar, R.; Chedid, R. A simulation model for reliability-based appraisal of an energy policy: The case of Lebanon. Energy Policy 2012, 45, 293-303. [CrossRef]

8. Bassil, G. Policy Paper for the Electricity Sector; Ministry of Energy and Water: Beirut, Lebanon, 2010.

9. Kinab, E.; Elkhoury, M. Renewable energy use in Lebanon: Barriers and solutions. Renew. Sustain. Energy Rev. 2012, 16, 4422-4431. [CrossRef]

10. Najjar, M.B.; Ghoulam, E.; Fares, H. Mini renewable hybrid distributed power plants for Lebanon. Energy Procedia 2012, 18, 612-621. [CrossRef]

11. Ibrahim, O.; Fardoun, F.; Younes, R.; Louahlia-Gualous, H.; Ghandour, M. Multivariable optimization for future electricity-plan scenarios in Lebanon. Energy Policy 2013, 58, 49-56. [CrossRef]

12. World Bank. Republic of Lebanon, Electricity Sector Public Expenditure Review; Report No. 41421-LB; World Bank: Washington DC, USA, 2008.

13. LaCommare, K.H.; Eto, J.H. Cost of power interruptions to electricity consumers in the United States (US). Energy 2006, 31, 1845-1855. [CrossRef]

14. Praktiknjo, A.J.; Hahnel, A.; Erdmann, G. Assessing energy supply security: Outage costs in private households. Energy Policy 2011, 39, 7825-7833. [CrossRef]

15. Praktiknjo, A.J. Stated preferences based estimation of power interruption costs in private households: An example from Germany. Energy 2014, 76, 82-90. [CrossRef]

16. Carlsson, F.; Martinsson, P. Does it matter when power outage occurs?-A choice experiment study on the willingness to pay to avoid power outages. Energy Econ. 2008, 30, 1232-1245. [CrossRef]

17. Carlsson, F.; Martinsson, P.; Akay, A. The effect of power outages and cheap talk on willingness to pay to reduce outages. Energy Econ. 2011, 33, 790-798. [CrossRef]

18. Nooij, M.; Bijvoet, C.C.; Koopmans, C.C. The value of supply security: The costs of power interruptions: Economic input for damage reduction and investment in networks. Energy Econ. 2007, 29, 277-295. [CrossRef] 
19. Reichl, J.; Schmidthaler, M.; Schneider, F. The value of supply security: The costs of power outages to Austrian households, firms and the public sector. Energy Econ. 2013, 36, 256-261. [CrossRef]

20. Linares, P.; Rey, L. The costs of electricity interruptions in Spain: Are we sending the right signals? Energy Policy 2013, 61, 751-760. [CrossRef]

21. Kufeoglu, S.; Lehtonen, M. Interruption costs of service sector electricity customers, a hybrid econometric model. Int. J. Electr. Power Energy Syst. 2015, 64, 588-595. [CrossRef]

22. Zachariadis, T.; Poullikkas, A. The cost of power outage: A case study from Cyprus. Energy Policy 2012, 51, 630-641. [CrossRef]

23. Wijayatunga, P.; Jayalath, M.S. Assessment of economic impact of electricity supply interruptions in the Sri Lanka industrial sector. Energy Conserv. Manag. 2004, 45, 235-247. [CrossRef]

24. Diboma, B.S.; Tatietse, T.T. Power interruption costs to industries in Cameroon. Energy Policy 2013, 62, 582-592. [CrossRef]

25. Kim, K.; Nam, H.; Cho, Y. Estimation of the inconvenience cost of a rolling blackout in the residential sector: The case of South Korea. Energy Policy 2015, 76, 76-86. [CrossRef]

26. Beenstock, M.; Goldin, E.; Haitovsky, Y. Response bias in a conjoint analysis of power outages. Energy Econ. 1998, 20, 135-156. [CrossRef]

27. Corwin, J.; Miles, W. Impact Assessment of the 1977 New York City Blackout; US Department of Energy: Washington, DC, USA, 1978.

28. Rose, A.; Oladosu, G.; Shu-Yi, L. Business interruption impacts of a terrorist attack on the electric power system of Los Angeles: Customer resilience to a total blackout. Risk Anal. 2007, 27, 513-531. [CrossRef] [PubMed]

29. Ministry of Energy and Water. Onshore and Offshore Electricity Produced by EDL; Unpublished work. Ministry of Energy and Water: Beirut, Lebanon, 2015.

30. Praktiknjo, A. The value of lost load for sectoral load shedding measures: The German case with 51 sectors. Energies 2016, 9, 116. [CrossRef]

(C) 2016 by the authors; licensee MDPI, Basel, Switzerland. This article is an open access article distributed under the terms and conditions of the Creative Commons Attribution (CC-BY) license (http://creativecommons.org/licenses/by/4.0/). 